\title{
Recurrent Childhood Anaplastic Oligoastrocytoma
}

National Cancer Institute

\section{Source}

National Cancer Institute. Recurrent Childhood Anaplastic Oligoastrocytoma. NCI

Thesaurus. Code C115358.

The reemergence of anaplastic olig oastrocytoma in childhood after a period of remission. 